\title{
Design and simulation of an MPPT charge controller for a PV application
}

\author{
Bidjagare Akiza ${ }^{1}$, Edjadessamam Akoro ${ }^{1}$, and Dam-Bé L. Douti ${ }^{1}$ \\ ${ }^{1}$ Laboratoire Matériaux et Energie Renouvelable, Université de Kara, UK
}

\begin{abstract}
In this document, we propose an MPPT charge controller based on the two-phase charging method proposed by the datasheet of the battery under test. Also, for efficient and optimal charge the charge controller reacts with better exploitation of the available photovoltaic (PV) power by means of a maximum power point tracking (MPPT) technique employed in the control algorithm especially the Perturb and observe (P\&O) techniques; when threshold voltage reach, the regulation phase start. The MPPT and converter efficiency are respectively $98.7 \%$ and $98.2 \%$ at the standard test condition (STC).
\end{abstract}

Keywords: photovoltaic, MPPT, battery

\section{Introduction}

Autonomous photovoltaic systems with storage have become more and more widespread in recent years, especially in rural areas isolated from the local energy distribution network. The type of storage generally used in these systems are lead-acid batteries. The maturity of this technology and its low cost are the main reasons[1]. Also, lead-acid batteries have a high number of cycles and represent about $15 \%$ of the initial investment but over an operating lifetime of twenty years, they could exceed $50 \%$ of the overall cost of the system ; it is therefore important to increase the life of the component to lower the cost of the energy produced[2]. And to get there, it requires an optimal use of these batteries, that is to say a charge/discharge controller. It is in this sense that we present in this document an algorithm for charging a lead-acid battery based on the (maximum power point tracking) MPPT method. This algorithm allows us to reach a state of charge of $100 \%$ while not exceeding the charge threshold voltage.

\section{Principle of an MPPT}

To optimize the power available from the panels we need an MPPT. The MPPT commands will continuously adjust the duty cycle associated to the static converter that charges the battery. Different MPPT methods have been published in the literature in order to obtain an optimal functioning. Many researchers are interested in recalling and comparing the different MPPT techniques that exist in the literature [으, 4$]$. BELKAID ABDELHAKIM shows in his thesis that there are about thirty MPPT techniques[5]. These MPPT command can be compared according to their dependencies on the parameters of the solar panels and their complexities and the type of implementation according to whether it is analogue, digital or mixed[$[\underline{3}, \underline{6}, \underline{7}]$. Among these commands the most knows are : the command called perturb and observed (P\&O), the incrementation of the conductance (IncCond), the approach of the constant current, the constant voltage[7] and in recent years the approach to fuzzy logic and the neuron network. Only the P\&O will be presented in this document. 


\section{Principle of P\&O command}

As its name indicates it is based on the disturbance of the system through the increase or decrease of $\mathrm{V}_{\text {ref }}$ or by acting directly on the duty cycle of the DC-DC converter, then by the observation of the effects of these disturbances on the panel output power. If the value of the current power $P(k)$ of the panel is greater than the previous value $P(k-1)$ then we reverse the direction of the disturbance. The algorithm flowchart is given below:

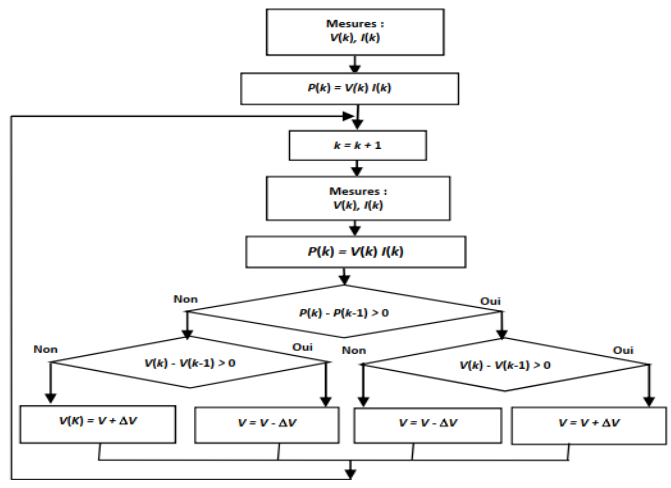

Figure 1. P\&O command flowchart[8].

\section{Design and sizing of a PV system charge controller}

The conversion chain of a PV system with storage is presented as illustrated in the figure 2 . It consists of a solar panel which acts as a generator, a DC-DC converter which ensures an adaptation between the generator and the battery, a charge controller that regulate the converter and finally the lead-acid battery which represents the charge.

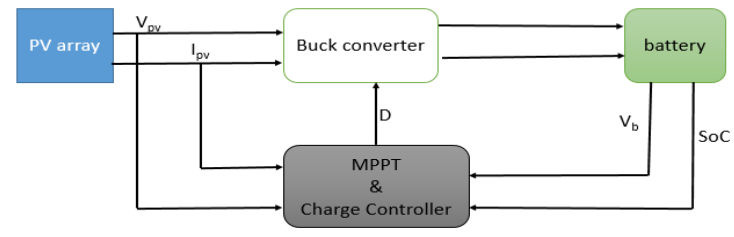

Figure 2. Battery charging system

\section{The solar panel and the DC-DC converter}

For the simulation we have used the "aleo solar A18.240" panel in the matlab library. The main electrical characteristics are maximal power, maximal voltage and maximal current which is respectively equal $240 \mathrm{~W}, 30.1 \mathrm{~V}$ and $8 \mathrm{~A}$.

The choice of buck DC-DC converter is motivated by the fact that the panel voltage is higher than one of the battery, and we need to lower it before charging the battery.

The equation (1) are given for the sizing of the filter at the output of the converter which limit current and voltage ripples. [8-10] :

$$
\text { - } L \geq \frac{\mathrm{Ve}}{\Delta I s * f c} \mathrm{D}(1-\mathrm{D}) \quad C \geq \frac{(1-\mathrm{D})}{8 * L * f c * f C}\left(\frac{V s}{\Delta V s}\right)
$$

$\mathrm{V}_{\mathrm{e}}$ : Maximal input voltage $(30 \mathrm{~V}), \mathrm{V}_{\mathrm{s}}$ : Maximal output voltage $(12 \mathrm{~V}), \mathrm{f}_{\mathrm{c}}$ : Switching frequency $(750 \mathrm{~Hz}), \Delta I s$ : Ripples output voltage and current $\left(5 \%\right.$ of $\mathrm{V}_{\mathrm{s}}$ and of $\left.\mathrm{I}_{\mathrm{s}}\right)$, D: Duty cycle.

The choice of the switching frequency is crucial. The larger it is, smaller is the core of the inductor and greater the switching losses of power[11]. 


\section{The algorithm of the MPPT charge regulator}

The charging of a battery follows two basic steps for an efficient charge without the risk of damaging the battery and also optimized a battery life time[2, 8]. The charging mode is represented by the following curve:

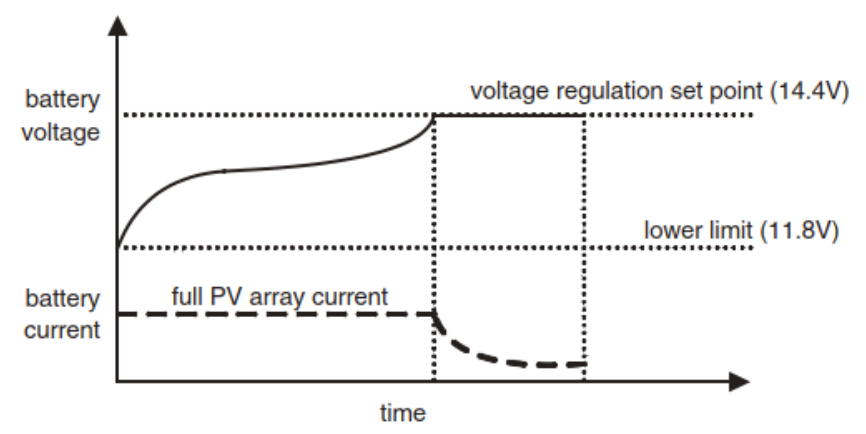

Figure 3. two-phase charging mode.

First, the battery is charged at constant current of around $\mathrm{C} / 5$ of its nominal capacity until the voltage at the battery terminal reaches the charging threshold voltage (14.4 V); then in a second charging phase, the voltage is kept constant at its threshold value until it is fully charge $(100 \%)$ with a progressive decrease of charge current. Starting from the charge principle described above the flow chart of the MPPT regulator is presented below:

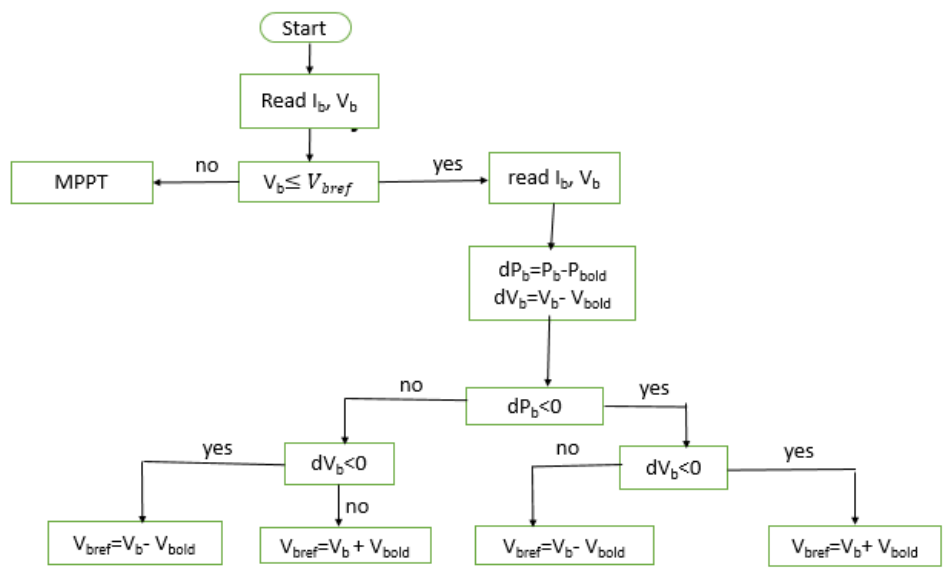

Figure 4. MPPT charge controller algorithm.

\section{Simulation : results and analyses}

For the simulations, we used the matlab/Simulink software. The capacity of battery over charge is 200Ah with nominal voltage at $12 \mathrm{~V}$. The test is done at STC condition.

At start of the charge, the maximum available PV power is transferred to the battery, according to the MPPT algorithm (Figure 6). Then the battery voltage progressively increase until it reaches 13.4V (Figure 5). Then the charge-regulation phase is initiated (Figure 5) and the battery charging current is progressively reduced to the defined value. Figure 6 shows the charging power variation when the regulation phase start. The efficiency of the converter and MPPT during all the charging process is lying between $97.3 \%$ and $98.7 \%$. We can see on figure $6 a$ that MPPT response is less than $0.01 \mathrm{~s}$. 

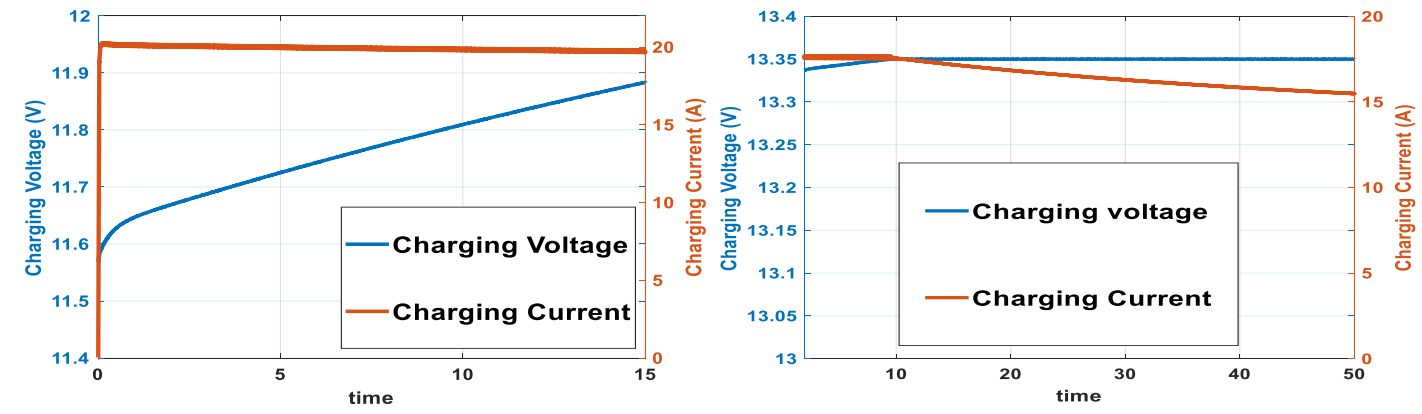

Figure 5. Voltage and current charging curve at the beginning and regulation phase.
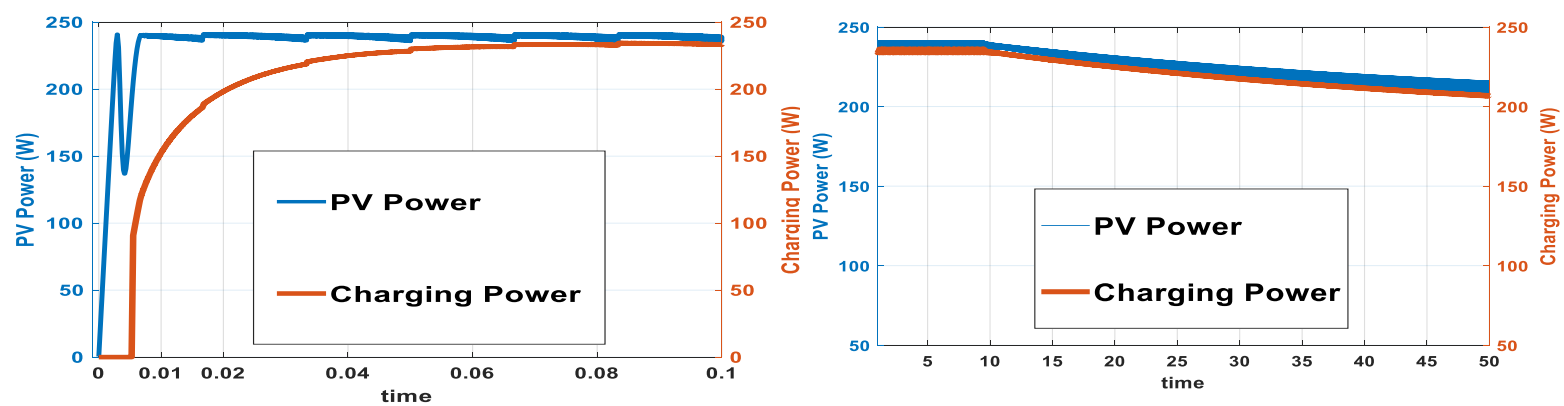

Figure 6. PV Power and charging Power at the beginning and regulation phase

\section{Conclusion}

In this document, we have studied the implementation of a two-phase MPPT charge controller with the aim of making an efficient charge allowing to prolong the life of the battery and other side save forward the fact that the use of an MPPT charge regulator reduces battery time charge for photovoltaic application by providing the maximum available power with an efficiency over $98 \%$.

\section{References}

[1] Mohammed B. Modeling the parameter of a lead-acid battery and it integration into an autonomous photovoltaic system. Université Abou Bekr Belkaid Tlemcen; 2015, p.8.

[2] MERROUCHE W, MALEK A. Development under PROTEUS of a regulator based on an eficient charging algorithm safe for lead acid batteries in a system photovoltaic. 2ème International seminaron new Energies and renewables. 2012, 8.

[3] Cédric C. Energy optimization of the electonic adaptation stage dedicated to photovoltaic conversion. Université de Toulouse; 2008, p. 162.

[4] Reza Reisi A, Hassan Moradi M, Jamasb S. Classification and comparison of maximum power point tracking techniques for photovoltaic system: A review. Renewable and Sustainable Energy Reviews. 2013 03;19:433-443. https://doi.org/10.1016/j.rser.2012.11.052

[5] ABDELHAKIM B. Design and implementation of an MPPT control of high performance for a conversion chain autonomous photovoltaic system. Université Ferhat Abbas setif1; 2015, p. 99.

[6] TAFTICHT T. Analysis and control of a hybrid system wind photovoltaics. Université du Québec à Trois-Rivières; 2006, pp.1-74.

[7] Ajaamoum, M. Comparison of the takagi-sugeno fuzzy controller and "P\&O"command for extracting the maximum power from a photovoltaic system. International Journal of Innovation and Applied Studies. 2015;10(1):192-206. 
[8] Souleyman F, Omar E. Study and realization of a commanded boost chopper by the microcontroller arduino in order to implement MPPT orders. Université Ahmed Draia Adrar; 2019, p. 67.

[9] Omar M. Design and production of a photovoltaic generator fitted with an MPPT converter for better energy management. Université Abou Bekr Belkaid Tlemcen; 2011.

[10] Amine M. The sliding mode control of two-level boost chopppers. ESSA; 2019, p.52.

[11] Abdellatif M. Study and optimization of a hybrid wind-photovoltaic system. Université Ferhat Abbas setif1; 2014, p.100. 